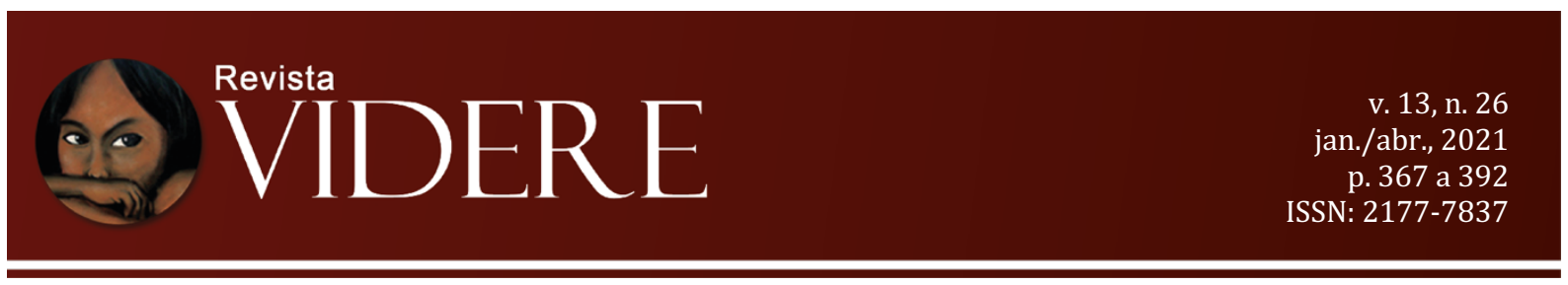

\title{
SOBREPOSIÇÃO DE ÁREA PROTEGIDA EM TERRITÓRIO TRADICIONAL: O CASO DO PARQUE NACIONAL DO JAÚ E O QUILOMBO DE TAMBOR, AMAZONAS, BRASIL ${ }^{1}$
}

\author{
OVERLAP OF PROTECTED AREA IN ETHNIC TERRITORY: THE CASE OF JAÚ \\ NATIONAL PARK AND TAMBOR'S QUILOMBO, AMAZONAS, BRAZIL
}

ÁREA PROTEGIDA SUPERPUESTA EN TERRITORIO ETNICO: EL CASO DEL PARQUE NACIONAL JAÚ Y EL PALENQUE DE TAMBOR, AMAZONAS, BRASIL

\author{
José Heder Benatti \\ Doutor em Ciências e Desenvolvimento Sustentável \\ Clínica de Direitos Humanos da Amazônia (CIDHA) / UFPA \\ E-mail: jbenatti@ufpa.br \\ OrcidID: 0000-0003-1159-912X
}

Resumo: O estudo analisa a possibilidade de proteger a diversidade cultural e ambiental, investigando a sobreposição do Parque Nacional do Jaú em território quilombola do Tambor, no estado do Amazonas, Brasil. O conflito divide-se em: momento de resistência após a criação do Parque; e período quando surge a reinvindicação de reconhecimento do quilombo do Tambor. Discutimos a relevância dos territórios tradicionais para a proteção da diversidade cultural e da biodiversidade. Adotamos o raciocínio dedutivo, o levantamento da literatura que trata do caso estudado e revisão bibliográfica acerca de proteção ambiental, biodiversidade e diversidade cultural. $O$ trabalho foi construído a partir de uma visão crítica e ampla da problemática do direito para examinar a realidade e a legislação socioambiental que rege o litígio. Concluímos que é imprescindível a criação de mecanismos administrativos e jurídicos

\footnotetext{
${ }^{1} \mathrm{O}$ trabalho é um dos produtos do Projeto "Impacto da Nova Legislação de Regularização Fundiária nas Terras Tradicionalmente Ocupadas pelas Comunidades Tradicionais", com bolsa de Produtividade CNPq (Processo CNPq: 308008/2018-9). Também contou com financiamento do Projeto "A Sobreposição de Unidades de Conservação em Territórios de Populações Tradicionais”, bolsa PIBIC/FAPESPA, em 2017, e o Projeto "Geração de Renda e a Proteção dos Recursos Naturais: alternativas para o desenvolvimento sustentável na Amazônia", com financiamento da CAPES - Programa Pró-Amazônia: Biodiversidade e Sustentabilidade. Uma versão preliminar foi apresentada no X Congreso de la Red Latinoamericana de Antropología Jurídica (RELAJU), realizado de 11 a 13 de outubro de 2018, em Temuco, Chile.

Agradeço a participação da Izabella Castro de Oliveira, que como graduanda e bolsista de iniciação científica na Clínica de Direitos Humanos da Amazônia (CIDHA/UFPA), bolsa FAPESPA em 2017, colaborou no levantamento das informações e organização do relatório do projeto. Sem a sua colaboração o trabalho seria limitado.
} 
para solucionar os conflitos entre direito das comunidades tradicionais ao território e a sobreposição a unidades de conservação de proteção integral, respeitando a diversidade cultural e a proteção da natureza.

Palavras-chave: Área protegida. quilombo. sobreposição territorial.

Abstract: The study examines the possibility of protecting cultural and environmental diversity, investigating the overlapping of the Jaú National Park in quilombola territory of Tambor, state of Amazonas, Brazil. The conflict is divided: time of resistance after the creation of the Park; period when the claim for recognition of the Tambor Quilombo arises. We discussed the relevance of traditional territories for the protection of cultural diversity, as well as for the conservation of the forest and biodiversity. We adopt deductive reasoning, a survey of the literature that deals with the case studied and a bibliographic review about environmental protection, biodiversity and cultural diversity. The work was built from a critical and broad view of the problem of law to examine the reality and the socio-environmental legislation that governs the litigation. We conclude that it is essential to create administrative and legal mechanisms to resolve conflicts between the right of traditional communities to the territory and the overlapping of the protected area with full protection, respecting cultural diversity and the protection of natural resources.

Keywords: Protected areas. quilombo. territorial overlaps.

Resumen: El estudio analiza la posibilidad de proteger la diversidad cultural y ambiental, investigando la superposición del Parque Nacional Jaú en territorio quilombola (palenques) de Tambor, en el estado de Amazonas, Brasil. El conflicto se divide en: momento de resistencia tras la creación del Parque; y período en el que surge el reclamo por el reconocimiento del quilombo do Tambor. Discutimos la relevancia de los territorios tradicionales para la protección de la diversidad cultural y la biodiversidad. Adoptamos el razonamiento deductivo, un relevamiento de la literatura que trata el caso estudiado y una revisión bibliográfica sobre protección ambiental, biodiversidad y diversidad cultural. La obra se construyó desde una visión crítica y amplia de la problemática del derecho para examinar la realidad y la legislación socioambiental que rige el litigio. Concluimos que es fundamental la creación de mecanismos administrativos y legales para resolver los conflictos entre el derecho de las comunidades tradicionales al territorio y la superposición de áreas protegidas de protección integral, respetando la diversidad cultural y la protección de la naturaleza.

Palabras clave: Area protegida. palenques. superposición territorial.

\section{INTRODUÇÃO}

Desde o final do século passado, inseriu-se no cenário nacional o debate sobre as duas formas de gestões territoriais que se justapõem: a identidade étnica, pela qual se busca assegurar o reconhecimento ao território tradicional mediante diferentes categorias fundiárias (terra indígena, quilombo, reserva extrativista, reserva do desenvolvimento sustentável, projeto de assentamento agroextrativista, projeto de desenvolvimento sustentável e projeto de assentamento florestal); e a criação de unidades de conservação de proteção integral que 
excluem a presença humana. Portanto, para cada uma dessas formas, há legislações distintas que reconhecem a diversidade cultural e a preservação ambiental.

No âmbito do debate político, as duas formas de gestão territorial são apresentadas em dicotomia ou como conflito de dois direitos constitucionais, em que, de um lado, há a discussão da manutenção dos modos de vida dos povos e comunidades tradicionais ${ }^{2}$ e, de outro lado, o pleito para garantir a preservação ambiental sem gente. Em outras palavras, a discussão é delineada de forma excludente entre a proteção da sociobiodiversidade ou a garantia da biodiversidade (SANTILLI, 2005). Assim, estaríamos diante de duas realidades distintas e inconciliáveis, de modo que deveríamos optar ou por uma ou por outra.

De fato, a discussão principal apresentada é a relação do ser humano com a natureza, a fim de elucidar se há possibilidade de convivência, ou se a presença humana é causadora de distúrbio que impossibilita a resiliência da natureza para voltar a sua condição original de equilíbrio, ou ainda algo próximo disso.

Para melhor entender a disputa entre as concepções conservacionista e a preservacionista $^{3}$, analisaremos o caso do Parque Nacional do Jaú (PARNA-Jaú), uma unidade de conservação (UC) de proteção integral (UCPI), localizada no estado do Amazonas, no médio rio Negro, na Amazônia Central, criada em 1980 por decreto presidencial, com uma área de 2.272.000 hectares. Foram analisados documentos oficiais, dissertações e trabalhos científicos sobre a temática. Além do levantamento de informações oficiais e acadêmicas, contamos com a experiência pessoal do primeiro autor deste texto, que, de 1995 a 1997, prestou consultoria

${ }^{2}$ Definimos comunidades tradicionais, ou populações tradicionais, como um conceito aberto, com os seguintes elementos caracterizadores: possuir uma ligação com um território determinado; uma organização social e política; uma relação com a natureza e o uso dos recursos naturais renováveis; e um pequeno grau de envolvimento com o mercado e a sociedade do entorno (ALMEIDA, 2004, 2011; ARRUTI, 2006; DIEGUES, 1994). Como lembra Barreto Filho (2006), a força do termo “populações tradicionais" encontra-se na sua generalidade e fluidez. Com a mesma compreensão, Manuela Carneiro da Cunha e Mauro Almeida (2001) afirmam que a abrangência não pode ser entendida como confusão conceitual. Para este estudo, as comunidades quilombolas estão incluídas na definição de comunidades tradicionais. Preferimos empregar a categoria comunidade tradicional devido ao conceito estar previsto no Decreto $n^{0} 6040 / 2007$, que institui a Política Nacional de Desenvolvimento Sustentável dos Povos e Comunidades Tradicionais (BRASIL, 2007, inciso I, art. $3^{\circ}$ ).

${ }^{3}$ Quando empregarmos a expressão "proteção do meio ambiente, bens ambientais, dos recursos ambientais ou naturais", estaremos nos referindo às ações que buscam a conservação e a preservação desses recursos. Conservação significa proteção dos recursos naturais, com a utilização racional, garantindo sua sustentabilidade para o uso das gerações presentes e futuras. A preservação visa a garantir a integridade e a perenidade do bem ambiental ou de uma área determinada. O termo "preservação" é empregado para designar a proteção integral dos recursos naturais. Portanto, são duas ações com objetivos distintos, mas que podem ser conjugadas. Essa distinção de significados é adotada também na literatura internacional. 
jurídica à Fundação Vitória Amazônica (FVA), colaborando na elaboração do Diagnóstico Fundiário do PARNA-Jaú, a fim de escrever o plano de manejo da unidade de conservação.

Neste trabalho, empregaremos o termo território tradicional como aquele mais próximo das definições atribuídas pela Antropologia, a qual enfatiza a apropriação e a construção simbólica feitas pelos povos e comunidades tradicionais nos espaços que habitam; portanto, não o abordamos como a teoria política e o ordenamento jurídico o concebem (um povo, um território, uma nação). Para o direito, território é um dos elementos formadores do estado e o limite de seu poder. O art. 3丷, I do Decreto Federal 6.040/2007 (BRASIL, 2007) define como territórios tradicionais os espaços necessários à reprodução cultural, social e econômica dos povos e comunidades tradicionais, sejam eles utilizados de forma permanente ou temporária, observando-se, no que diz respeito aos povos indígenas e quilombolas, respectivamente, o que dispõem os arts. 231 da CF e 68 do Ato das Disposições Constitucionais Transitórias e demais regulamentações (BRASIL, 1988).

\section{AS COMUNIDADES TRADICIONAIS E O PARQUE NACIONAL DO JAÚ (PARNA- Jaú)}

As primeiras áreas protegidas criadas no Brasil tinham o objetivo de proteger a integridade dos ecossistemas, a biodiversidade e os serviços ambientais. Portanto, o que legitimava a atitude do Poder Público de afetar uma gleba de terra com fim ambiental eram a conservação do solo, a proteção das bacias hidrográficas, o combate à erosão, a reciclagem de nutrientes, o equilíbrio climático, a preservação de alguma espécie da fauna ou flora endêmica naquela área etc.

Apesar da tendência internacional de adotar o termo área protegida para designar as áreas criadas pelo Poder Público a fim de preservar ou conservar espaços de relevâncias naturais e/ou culturais, a burocracia brasileira preferiu utilizar a denominação unidade de conservação. Este termo foi mais tarde adotado pelos diferentes segmentos sociais e previsto legalmente, com a Lei do SNUC - Lei 9.985/2000 (BRASIL, 2000a). Empregamos neste texto área protegida (ou área legalmente protegida) como gênero, pois as espécies são as unidades de conservação, terras indígenas e quilombolas, reserva legal, área de preservação permanente etc. Seguimos a definição dada pelo Decreto 5.758/2006 (BRASIL, 2006), que institui o Plano Nacional de Áreas Protegidas (PNAP), que por sua vez legitimou a definição de 2008 apresentada pela União Internacional para a Conservação da Natureza (IUCN em inglês) que declara: "Uma área protegida é um espaço geográfico claramente definido, reconhecido, 
dedicado e gerenciado, através de meios legais ou outros meios efetivos, para alcançar a conservação a longo prazo da natureza com serviços ecossistêmicos e valores culturais associados" (INTERNATIONAL UNION FOR CONSERVATION OF NATURE, [20--], online $)^{4}$.

No âmbito das políticas públicas, somente as unidades de conservação eram consideradas áreas protegidas. A partir de 2006, o Plano Estratégico Nacional de Áreas Protegidas (PNAP) incluiu neste conceito os territórios indígenas e quilombolas via Decreto 5.758/2006, pois o governo federal reconheceu que essas categorias fundiárias também abrangem "áreas naturais definidas geograficamente, regulamentadas, administradas e/ou manejadas com objetivos de conservação e uso sustentável da biodiversidade" (BRASIL, 2006).

A partir da década de 1990, o escopo de criação foi ampliado e atualmente também inclui a proteção dos territórios dos povos indígenas e comunidades tradicionais. Contudo, quando há conflito (sobreposição) de interesses, os direitos territoriais dos povos e comunidades tradicionais são ignorados, como se estes fossem grupos sociais invisíveis (SOUZA FILHO, 2015; CHAGAS, 2010; VIANNA, 2008).

Não temos dados totais sobre a quantidade de unidades de conservação que sobrepõe os territórios dos povos e comunidades tradicionais em terras estaduais e federais, mas, de acordo com o Ministério do Meio Ambiente (BRASIL, [20--]), são 82 (oitenta e duas) unidades de conservação federais sobrepostas a terras indígenas, quilombos e de comunidades tradicionais. O levantamento do Instituto Socioambiental (ISA) em relação às populações indígenas, até o ano de 2014, computava 48 (quarenta e oito) superposições, envolvendo 35 (trinta e cinco) terras indígenas e 34 (trinta e quatro) unidades de conservação (RED AMAZÓNICA DE INFORMACIÓN SOCIOAMBIENTAL GEORREFERENCIADA, 2016, p. 79). Estimam-se para os territórios quilombolas 6 (seis) sobreposições, três (3) com parques nacionais e a outra metade em reservas biológicas (ABIRACHED; BRASIL; SHIRAISHI, 2010). As sobreposições fundiárias em território quilombola são as seguintes: Parque Nacional de Cabo Orange e território quilombola de Cunani, Amapá; Reserva Biológica Mata Escura e território quilombola Mumbuca, Minas Gerais; Reserva Biológica Rio Trombetas e território quilombola Alto Trombetas, Pará; Reserva Biológica do Guaporé e território quilombola de Santo Antônio do Guaporé, Rondônia; Parque Nacional do Jaú e território quilombola Tambor,

\footnotetext{
${ }^{4}$ No original: "A protected area is a clearly defined geographical space, recognised, dedicated and managed, through legal or other effective means, to achieve the long term conservation of nature with associated ecosystem services and cultural values". Para aprofundar o assunto, conferir Pereira e Scardua (2008).
} 
Amazonas; Parque Nacional de Aparados da Serra e da Serra Geral e território quilombola São Roque, Santa Catarina e Rio Grande do Sul (CHACPE, 2014).

Dentro do primeiro contexto é que foi criado o Parque Nacional do Jaú, uma unidade de conservação de proteção integral, situada no estado do Amazonas, cujo objetivo principal é a preservação dos recursos naturais, sem a presença humana.

As ideias que fundamentaram a criação do PARNA-Jaú partiram de alguns pesquisadores, principalmente zoólogos e botânicos, que começaram a analisar alguns dados de distribuição geográfica de organismos vegetais, segundo a Teoria dos Refúgios proposta por Haffer, em 1969, que acabou influenciando a burocracia estatal responsável pela criação de unidades de conservação e na definição das áreas consideradas prioritárias para preservação, que também ganhou simpatia de segmentos do movimento ambientalista. A teoria dos refúgios defende que

[...] a persistência de grandes manchas de florestas tropicais úmidas durante os períodos secos do Terciário e do Quaternário, especialmente aquelas localizadas próximas de superfícies rebaixadas, sobretudo nas porções periféricas da Amazônia. Essas áreas são, provavelmente, a origem de muitas espécies e subespécies de plantas e animais existentes hoje em dia. Os "refúgios" úmidos podem ter sido separados por vários tipos de savana e florestas secas, como também por outros tipos de vegetação intermediária de climas sazonalmente secos (HAFFER; PRANCE, 2002, p. 206).

Com base nessa teoria, foram escolhidas as áreas que sobrepunham sempre a dois ou mais refúgios determinados por diferentes cientistas, pois os dados preliminares não asseguravam com precisão os contornos das áreas prioritárias. Nessa perspectiva, foi proposta, em 1979, a criação de uma Reserva Biológica (REBIO) na área, sendo em seguida modificada para Parque Nacional, em virtude de as REBIOs serem bastante restritas à visitação pública (FUNDAÇÃO VITÓRIA AMAZÔNICA, 1998).

O Parque Nacional do Jaú foi criado pelo Decreto $\mathrm{n}^{\circ} 85.200$, de 24 de setembro de 1980 (BRASIL, 1980), sendo considerado por muitos anos o maior Parque Nacional do Brasil 5 . O Parque está aproximadamente $220 \mathrm{~km}$ a noroeste de Manaus, entre os municípios de Novo Airão, Barcelos, Codajás e Rorainópolis, em plena floresta Amazônica, na bacia do rio Jaú, fazendo limite com o rio Carabinani, ao sul, e os rios Unini e Paunini, ao norte; O rio Negro forma o limite leste do Parque. A importância desse Parque para a preservação ambiental se

\footnotetext{
${ }_{5}^{5}$ De acordo com o MMA/IBAMA (BRASIL, 2009, p. 29), o Parque Nacional Montanhas do Tumucumaque é atualmente o maior Parque Nacional do Brasil e o maior em Florestas Tropicais do mundo. Sua abrangência de Leste a Oeste per faz $355 \mathrm{~km}$, de Norte a Sul $311 \mathrm{~km}$, aproximadamente, com 3.846.429,40 ha $\left(38.464 \mathrm{~km}^{2}\right)$.
} 
deve ao fato de ele ser a única bacia de águas pretas do mundo, tombado como sítio de patrimônio natural mundial pela UNESCO em 2000 (JOHN, 2003, on-line).

O artigo 11 da Lei 9.985/2000 (Sistema Nacional de Unidades de Conservação SNUC) declara que

O Parque Nacional tem como objetivo básico a preservação de ecossistemas naturais de grande relevância ecológica e beleza cênica, possibilitando a realização de pesquisas científicas e o desenvolvimento de atividades de educação e interpretação ambiental, de recreação em contato com a natureza e de turismo ecológico.

$\S 1^{\circ} \mathrm{O}$ Parque Nacional é de posse e domínio públicos, sendo que as áreas particulares incluídas em seus limites serão desapropriadas, de acordo com o que dispõe a lei (BRASIL, 2000a).

Como a implementação do Parque Nacional objetivava a preservação da natureza com a mínima interferência humana, as comunidades tradicionais e não tradicionais residentes na área da unidade de conservação tinham que ser retiradas. A partir de então, iniciou-se uma disputa por direitos que, até os dias atuais, ainda não foi completamente resolvida, deixando inúmeras famílias das comunidades tradicionais e quilombolas sem seu devido espaço e sem a autonomia quanto ao modo de vida. Nesse cenário, diversas formas de desrespeito foram praticadas.

Desde a criação do Parque Nacional do Jaú, em 1980, com as radicalizações das ações quando de sua implantação em 1985, as comunidades tradicionais residentes no Parque passaram a sofrer restrições em relação à utilização dos recursos naturais ${ }^{6}$. As pressões exercidas na época pelos funcionários do Instituto Brasileiro de Desenvolvimento Florestal (IBDF) e atualmente pelos do Instituto Chico Mendes de Conservação da Biodiversidade (ICMBio) e do Instituto Brasileiro do Meio Ambiente e dos Recursos Naturais Renováveis (IBAMA), resultaram em intimidações, perseguição referente à coleta de recurso madeireiro e não madeireiro e à caça para subsistência. As comunidades tradicionais começaram a se organizar para resistir à expulsão das áreas que tradicionalmente ocupavam e tiveram que alterar suas formas de uso e manejo dos recursos naturais devido à influência da Fundação Vitória Amazônica (FVA) 7 e do IBAMA (CREADO et. al., 2008; MENDES et. al., 2006). Por outro lado, as diferentes pressões causaram êxodo do parque que se estende-se temporal e

\footnotetext{
${ }^{6}$ O Parque Nacional do Jaú é ocupado por 886 moradores reunidos em 143 grupos domésticos, dos quais $47 \%$ estão vivendo em sete comunidades. A maioria dos moradores que vive no PNJ, 55\%, é oriunda de outras localidades do estado do Amazonas, 37\% nasceram no Parque e os outros 8\% são procedentes das regiões Norte e Nordeste (FUNDAÇÃO VITÓRIA AMAZÔNICA, 1998, p. 139).

${ }^{7}$ A Fundação Vitória Amazônica (FVA) é uma organização não governamental que trabalha na área do Parque Nacional do Jaú desde a década de 1990. A FVA e o IBAMA trabalharam em parceria desde 1993 para elaborar o Plano de Manejo do Parque Nacional do Jaú, que foi aprovado em 1998.
} 
espacialmente, com a saída de diversas famílias de moradores que vão reconstruir suas vidas nas cidades próximas, principalmente em Novo Airão (BARRETTO FILHO, 2001; PINHEIRO, 2003).

Várias tentativas foram empreendidas para remover as comunidades tradicionais do interior do Parque Nacional, em particular das margens do rio Jaú:

Com o intuito de efetuar as indenizações às famílias residentes na área do PNJ, em 1989, o IBAMA tentou realizar o pagamento, que foi prontamente recusado pelos moradores. Alegaram na ocasião que os valores das indenizações estavam abaixo do valor real a ser pago. Para que eles se retirassem da área, seria necessário atualizar os valores com critérios mais justos no cálculo das indenizações, e garantir a realocação por um projeto de assentamento (FUNDAÇÃO VITÓRIA AMAZÔNICA, 1998, p. 6).

Foram apresentadas algumas propostas para superar o impasse, inclusive a criação de um assentamento em outra cidade vizinha (Novo Airão), que foi inviabilizada por falta de verba para pagar indenizações às famílias; assim, as imposições colocadas pelo IBAMA dificultaram o modo de vida dos moradores do Parque e causaram revoltas (CAMPOS, 2006; CALDENHOF; FERREIRA, 2012).

No ano de 1985, o IBDF instalou na foz do rio Jaú uma base flutuante, iniciando a fiscalização da área do Parque. Nesse período, intensificou-se a pressão às comunidades tradicionais que estavam na área antes da criação do Parque. Essas comunidades foram coagidas a "sair" da UC, sem o reconhecimento de seus direitos à terra onde viviam e trabalhavam. Indiscutivelmente, essa violação é uma ilegalidade.

As reivindicações apresentadas pelos moradores do Parque continuam as mesmas até os dias atuais. Não há significativos resultados de solução quanto à posse definitiva da terra para as comunidades tradicionais, pois sua territorialidade está ameaçada diante das imposições e limitações deliberadas pelo órgão ambiental federal.

Diante do impasse, as comunidades tradicionais buscaram diferentes formas de resistência, dentre as quais está a reivindicação pelo reconhecimento da comunidade do Tambor como quilombola (Quilombo do Tambor). 


\section{QUILOMBO DO TAMBOR E O PARNA-Jaú: NECESSIDADE DE RECONHECIMENTO DO DIREITO AO TERRITÓRIO}

As comunidades Quilombolas têm a garantia de seus direitos territoriais previstos na Constituição Federal, com fundamento no artigo 68 do Ato das Disposições Constitucionais Transitórias (BRASIL, 1988). Nesse contexto,

Depois do reconhecimento do direito à terra, os desafios continuam, pois é necessário elaborar uma política de promoção da igualdade racial, que permita incluir as comunidades quilombolas nos benefícios que até hoje lhes foram negados: educação, saúde, saneamento básico, lazer, etc. Muitos obstáculos terão que ser vencidos, muitos conflitos terão que ser enfrentados, mas o sonho permanece. Um sonho que finca suas raízes numa convicção: a terra quilombola é um patrimônio histórico-cultural brasileiro e não uma simples mercadoria. Por isso é obrigação de toda a sociedade brasileira lutar para que este sonho vire realidade (TRECCANI, 2006, p. 22).

Aos quilombos se reconhece o direito de propriedade das terras que ocupam e em caráter definitivo. Assim, os títulos devem ser emitidos pelos órgãos responsáveis do Estado, verificando-se a competência. Por força do Decreto 4.887/2003 (BRASIL, 2003), o Instituto Nacional de Colonização e Reforma Agraria - INCRA é a autarquia competente, no âmbito federal, pela titulação desses territórios quilombolas ${ }^{8}$.

Os quilombos que surgiram a partir da fuga das plantations e engenhos representam outros casos de etnogênese cuja consolidação como grupo social se deu com o estabelecimento de territórios autônomos no interior da Colônia e a posterior defesa desses territórios frente a ataques externos, sendo a República de Palmares o caso mais conhecido (LITTLE, 2004, p. 256).

As terras ocupadas por remanescentes das comunidades dos quilombos são aquelas utilizadas para a garantia de sua reprodução física, social, econômica e cultural. Como parte de uma política de compensação histórica, a política de regularização fundiária de territórios quilombolas é de suma importância para a dignidade e garantia da continuidade desses grupos étnicos.

O Decreto 4.887/2003 foi o responsável por determinar de forma clara a definição do conceito das populações quilombolas e os elementos constitutivos do seu espaço, a demarcação e titulação dos territórios. De acordo com esse conceito, são considerados remanescentes de quilombos os grupos étnico-raciais, pautados nos critérios da autoatribuição, da trajetória histórica própria e que tenham relações com determinado território

\footnotetext{
${ }^{8}$ Recentemente o STF julgou improcedente a Ação Direta de Inconstitucionalidade (ADI) 3239 (BRASIL, [201]). O Relator Ministro Cezar Peluso, em 8/02/2018, reconheceu a aplicação da Convenção 169 para os quilombolas e a constitucionalidade do Decreto 4.887/2003.
} 
especificamente, compreensão de ancestralidade negra relacionada com a resistência à opressão historicamente sofrida (BRASIL, 2003).

Diante da proteção constitucional adquirida pelas comunidades quilombolas após a Constituição Federal de 1988, é evidente que o pedido de titulação como território quilombola, por parte das comunidades tradicionais que habitavam o local antes da criação do parque, é uma forma de resistência, para assegurar o modo de ser e viver. Há diferentes ações e estratégias acionadas por povos e comunidades tradicionais em face da ameaça de perda dos seus territórios tradicionalmente ocupados (SHIRAISHI NETO, 2011).

Isso, porque o pedido legal de reivindicação sobre a terra ocorre como uma reação na luta pela existência da comunidade do Tambor, que é um dos grupos sociais afetados com a criação do Parque. Entretanto, o pedido formal de reconhecimento só aconteceu posteriormente à efetiva criação do Parque Nacional do Jaú, em 2003.

A área quilombola sobreposta ao Parque está ocupada por vinte famílias. Outras dezenove famílias estão na área urbana do município de Novo Airão, estado do Amazonas. Portanto, um total aproximado de 40 famílias e 200 pessoas para um território de 719.000,0000 hectares, todo inserido no perímetro do Parque ${ }^{9}$ (Figura 1). O Instituto Chico Mendes alega que o uso efetivo da comunidade é de 40 mil hectares (CHACPE, 2014, p. 115).

Figura 1: Mapa da sobreposição do Parque Nacional do Jaú e o Território Quilombola do Tambor.

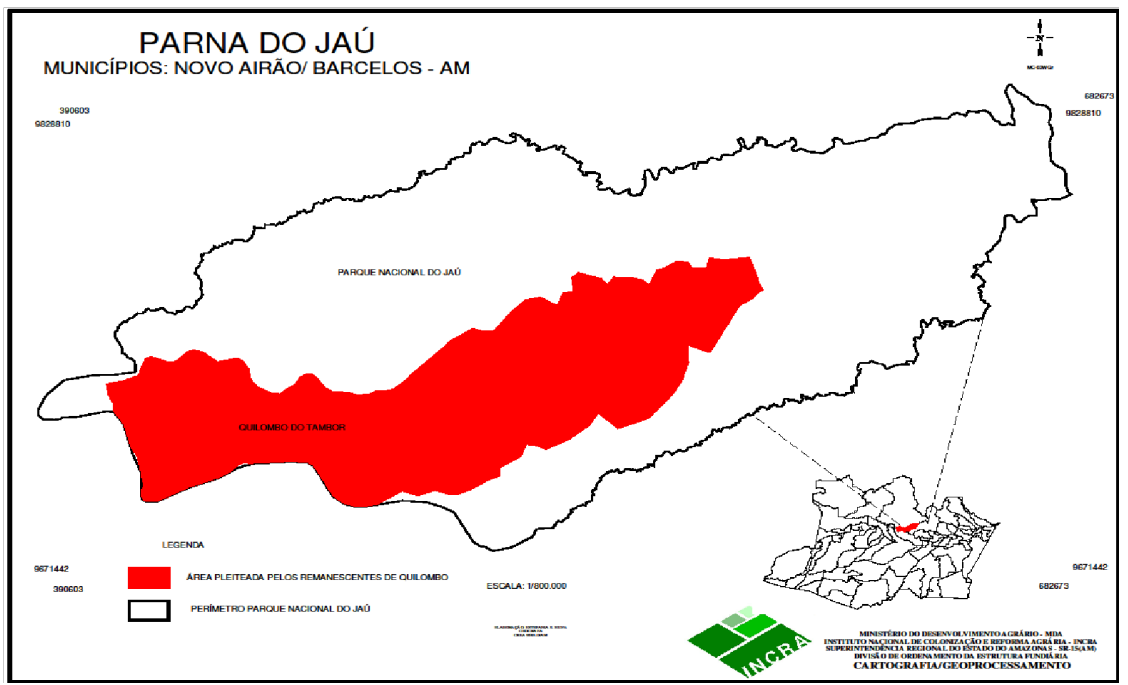

Fonte: INCRA e MMA (BRASIL, [20--]).

\footnotetext{
${ }^{9}$ Segundo Leite (2015, p. 46), a comunidade do Tambor era composta "por 25 famílias e 103 pessoas. Porém, o levantamento feito pela Associação dos Moradores Remanescentes de Quilombo da Comunidade do Tambor, concluiu que aproximadamente 33 famílias e 233 pessoas descendentes dos três casais pioneiros do rio dos pretos...".
} 
O reconhecimento da comunidade do Tambor como quilombola não aconteceu pacificamente, pois houve contestação por parte do IBAMA e da Fundação Vitória Amazônica. Desde 2003, os quilombolas reivindicam oficialmente o reconhecimento, que logrou êxito somente em 2006, com o reconhecimento da Fundação Cultural Palmares, a qual certificou a comunidade Tambor como remanescente de quilombo.

Desde o início do pedido de reconhecimento como comunidade quilombola, o órgão ambiental federal alega que, sob o aspecto histórico de ocupação do PARNA-Jaú, a comunidade do Tambor não se distingue de outras comunidades tradicionais que ocupam o Parque, como se as demais comunidades também não tivessem direitos ao território tradicional.

Foi no início do século XX que as primeiras famílias chegaram ao local denominado de Tambor, localizado no médio rio Jaú, em área central do PARNA-Jaú.

Em conformidade com o INCRA ${ }^{10}$, o Quilombo do Tambor reivindica uma área de 719.880,6773 ha, com um total de 17 famílias morando atualmente nela. Muitas dessas famílias foram deslocadas compulsoriamente do local, e sofrem com o descaso e demora com que o conflito é tratado.

A solicitação decorre das limitações no uso dos recursos naturais e até mesmo da expulsão de famílias residentes no Parque e da interpretação restritiva da legislação pelo órgão ambiental responsável pela criação da unidade de conservação.

É nítido que, durante a criação do Parque Nacional do Jaú, o órgão público responsável pela sua efetivação não levou em consideração as comunidades tradicionais que já viviam no local, evidenciando a situação da própria escolha de uma unidade de conservação de proteção integral, cujo impasse perdura até os dias atuais. A mesma prática de expulsão das comunidades tradicionais teve mais êxito no Parque Nacional de Anavilhanas, criada em 1981 (BRASIL, 1981), no baixo rio Negro, com uma área de 350.000 hectares. Inicialmente era uma Estação Ecológica de Anavilhanas, mas devido à pressão local para que possibilitasse o uso para fins turísticos, em 2008, a unidade de conservação foi alterada para Parque Nacional, pela Lei 11.799, de 29 de outubro (BRASIL, 2008; INSTITUTO SOCIOAMBIENTAL, [20--]).

\section{AS COMUNIDADES TRADICIONAIS E A PROTEÇÃO AMBIENTAL}

\footnotetext{
${ }^{10}$ Conforme dados do Instituto Nacional de Colonização e Reforma Agrária / Departamento Fundiário Quilombola (INCRA-DFQ), atualizados em setembro de 2016.
} 
Diante da discussão sobre o reconhecimento da importância das comunidades tradicionais para assegurar a diversidade cultural, o conhecimento sobre a natureza e a proteção ambiental, apresenta-se o debate da compatibilidade ou não entre cultura e natureza.

O avanço do desmatamento das florestas naturais, em particular na Amazônia, está levando à fragmentação de habitats e de biomas, causando a extinção da fauna e da flora. Como soluções encontradas para superar esse problema, destaca-se a elaboração leis que asseguram a proteção da floresta, da biodiversidade e a criação de unidade de conservação.

Nesse contexto, podemos citar como exemplo a Convenção Sobre Diversidade Biológica (CDB), ratificada pelo Decreto Legislativo n ${ }^{0} 2$, de 1994, que dispõe sobre o conceito de biodiversidade, delineando-o em seu artigo $2^{\circ}$ :

Diversidade biológica significa a variabilidade de organismos vivos de todas as origens, compreendendo, dentre outros, os ecossistemas terrestres, marinhos e outros ecossistemas aquáticos e os complexos ecológicos de que fazem parte; compreendendo ainda a diversidade dentro de espécies, entre espécies e de ecossistemas (BRASIL, 2000b).

Desde seu preâmbulo, a Convenção reconhece o valor inerente da biodiversidade. Nesse sentido, não é necessário que os recursos da biodiversidade já estejam sendo utilizados ou que se reconheça uma destinação específica para eles, pois, pelo simples fato de comporem a diversidade do planeta, merecem respeito, reconhecimento e proteção.

Os povos e as comunidades tradicionais são reconhecidos constitucionalmente e os seus direitos territoriais foram sendo incorporados ao sistema legal a partir de muitas reivindicações ocorridas ao longo dos últimos anos.

A Lei 9.985/2000, que regulamenta o Art. 225 da Constituição Federal e institui o Sistema Nacional de Unidades de Conservação da Natureza, faz referência específica ao termo “comunidades tradicionais" em seu artigo 17, ou "populações extrativistas tradicionais", artigo 18 (BRASIL, 2000a). Além disso, evidencia a relação entre comunidades tradicionais e as unidades de conservação que ocorre na área de proteção ambiental, floresta nacional, reserva extrativista e reserva de desenvolvimento sustentável.

Contudo, apesar dos avanços quanto ao reconhecimento e à importância desses grupos sociais - como a criação de legislações específicas -, as tensões e os conflitos ainda persistem em várias situações; dentre estes, cabe destacar a ausência de uma solução que assegure os direitos dos povos indígenas e comunidades tradicionais em áreas afetadas, com a criação de unidades de conservação de proteção integral, em particular os parques e reservas biológicas. 
Também pode haver conflito entre o gestor e as lideranças das comunidades tradicionais beneficiária da Unidade de Conservação de Uso Sustentável quando ocorre divergência de compreensão sobre a forma de gerir os recursos naturais da área protegida, já que o responsável legal pela gestão da unidade de conservação é um servidor do órgão ambiental e na prática tem a última palavra. ${ }^{11}$ Explica Almeida (2004) que um dos pontos conflitantes é o fato de o controle dos recursos naturais básicos não ser exercido de forma livre e individual por um determinado grupo que necessite deles para sua subsistência, por exemplo. As normas criadas para gestão da unidade de conservação para regulamentar o modo de vida das comunidades tradicionais residentes não são devidamente acordadas entre a parte diretamente afetada e os órgãos responsáveis pela elaboração dos documentos.

O conflito entre as comunidades tradicionais e o órgão gestor do PARNA-Jaú ocorre em virtude de haver um choque de concepções. De um lado, uma visão estritamente preservacionista, pautada na dicotomia ser humano e natureza. De outro, uma concepção com visão mais social, com fundamento no socioambientalismo.

A forma de se relacionar com as comunidades tradicionais que estão dentro do PARNA-Jaú demonstra o posicionamento ideológico assumido pelo órgão gestor do Parque, o qual se pauta numa visão mais rígida de preservação ambiental, sem inserir a presença humana como um elemento necessário ao equilíbrio da natureza.

Contrariamente à primeira visão, as comunidades tradicionais se fundamentam nos argumentos que sustentam o socioambientalismo. Defendem a convivência e o seu pertencimento dentro da unidade de conservação, bem como a proteção ambiental. De acordo com esse raciocínio, a maior eficácia e a sustentabilidade na proteção da natureza serão alcançadas se houver a integração das comunidades tradicionais. Por isto afirma-se que:

O socioambientalismo foi construído a partir da ideia de que as políticas públicas ambientais devem incluir e envolver as comunidades locais, detentoras de conhecimentos e de práticas de manejo ambiental. Mais do que isso, desenvolveu-se a partir da concepção de que, em um país pobre e com tantas desigualdades sociais, um novo paradigma de desenvolvimento deve promover não só a sustentabilidade estritamente ambiental, ou seja, a sustentabilidade de espécies, ecossistemas e processos ecológicos, como também a sustentabilidade social (SANTILLI, 2005, p. 14).

\footnotetext{
${ }^{11}$ Os conselhos das UC são regulados pela Instrução Normativa (IN) ICMBio no 09 , de 5 de dezembro de 2014. Esta norma disciplina as diretrizes, normas e procedimentos para formação, implementação e modificação na composição de Conselhos Gestores de Unidades de Conservação Federais. Mesmo que haja previsão no art. 15 da IN ICMBio 09/2014 que os conselhos deliberativos das UC de Uso Sustentável serão compostos majoritariamente por representantes das comunidades tradicionais beneficiárias, não é suficiente para garantir que seus interesses serão respeitados.
} 
Os posicionamentos com base não similares e as ações conflitantes evidenciam um dos principais pontos a originar o conflito da sobreposição do Parque Nacional do Jaú, que ocorre entre as comunidades tradicionais existentes no local e o órgão gestor.

\subsection{O impasse no uso dos recursos naturais do PARNA-Jaú pelas comunidades tradicionais}

O principal ponto de conflito entre as comunidades tradicionais em unidades de conservação de proteção integral (Estação Ecológica, Reserva Biológica, Parque Nacional, Monumento Natural e Refúgio de Vida Silvestre) é a concepção importada dos Estados Unidos, focalizando a preservação pautada na separação do ser humano da natureza (DIEGUES, 1994). Criou-se o entendimento de que natureza preservada é aquela em que se pode manter a área protegida totalmente livre e segura da ação humana.

Anos depois da criação do PARNA-Jaú, a Fundação Vitória Amazônica ficou responsável pela elaboração do Plano de Manejo, a fim de assegurar a conservação da natureza na bacia do rio Negro. Foi assinado em 1993 um convênio de cooperação técnico-científica entre o IBAMA e a FVA a fim de assegurar a elaboração do Plano de Manejo, que deveria ser realizado de forma participativa com os moradores do Parna-Jaú (FUNDAÇÃO VITÓRIA AMAZÔNICA, 1998).

Em abril de 1992, foram elaborados o Plano de Ação para a Consolidação do Parque Nacional do Jaú e o Plano de Manejo, os quais envolveram o IBAMA, responsável pela área, e demais agentes sociais, que delimitaram em conjunto as linhas de ação visando a sua proteção. Realizou-se levantamento socioeconômico, por domicílio, com o objetivo de recensear e demarcar as localidades, além de para conhecer os moradores e usuários do Parque. Foram empregadas tanto uma metodologia que asseguraria a participação das comunidades tradicionais quanto pesquisas realizadas na área da biologia e ecologia (FUNDAÇÃO VITÓRIA AMAZÔNICA, 1998).

Os estudos realizados reconheciam que se tratava de uma unidade de conservação de proteção integral ${ }^{12}$; contudo, foram surgindo opiniões favoráveis à possibilidade da manutenção dos moradores no Parque. Na análise de relatórios e do Plano de Manejo, verificouse que, no nível em que ocorrem, as atividades de extrativismo praticadas pelas comunidades tradicionais aparentemente não provocaram extinções da flora ou da fauna nem produziram

\footnotetext{
${ }^{12}$ O Art. 2 ${ }^{\circ}$, VI da Lei 9.985/2000 (Lei do SNUC), define como proteção integral a "manutenção dos ecossistemas livres de alterações causadas por interferência humana, admitido apenas o uso indireto dos seus atributos naturais" (BRASIL, 2000a).
} 
variações observáveis nas espécies da área. Os relatórios ambientais técnicos indicavam que as comunidades que ocupavam o Parque estavam localizadas na área de maior diversidade ecológica.

Contudo, as medidas implementadas pelo órgão ambiental federal proibiram o comércio e a captura de subsistência, implicando muita revolta entre os moradores do Parque e aumentando a tensão.

Especificamente sobre a extinção de espécies no PARNA-Jaú, os estudos indicavam que:

Apesar de muitas espécies serem usadas como alimento e um número menor no comércio, não há registro de extinção de espécies no PNJ [Parque Nacional do Jaú]. A caça por peles, que poderia ser uma ameaça, acabou há mais de 20 anos, segundo relato de vários moradores que caçaram para essa finalidade (FUNDAÇÃO VITÓRIA AMAZÔNICA, 1998).

As terras que compõem o Parque, vistas de um contexto jurídico, são encontradas em três situações distintas, quais sejam: as terras devolutas do estado do Amazonas, a maior parte; as terras sob o domínio privado; e as terras de apossamento das comunidades tradicionais. Para cada uma dessas situações, cabe um procedimento específico, com o intuito de incorporálas ao domínio público federal.

Os moradores do PNJ desenvolvem atividades agroextrativistas, base econômica que se coaduna com a atividade familiar, daí podermos caracterizar como posse agroecológica. Os produtos cultivados e a utilização de recursos naturais fazem parte da base econômica das comunidades tradicionais, demonstrando que sua subsistência e a troca do excedente estão embasadas em atividades econômicas bem diversificadas. As práticas das comunidades tradicionais são de baixo impacto ambiental, como também as tecnologias empregadas de exploração dos recursos naturais. Em relação ao mercado (venda ou troca de produtos e/ou mercadorias), esses grupos possuem baixa dependência, o que assegura a manutenção da integridade ecológica do ecossistema original.

No que tange ao apossamento e ao uso dos recursos naturais, a posse agroecológica é definida a partir da noção física, com a somatória dos espaços familiares e das áreas de uso comum. Ao se constituir em espaço ecológico e social interligado, ela se materializa em três conjuntos: casa, roça e floresta. Os espaços considerados de apropriação familiar estão relacionados ao produto do trabalho, por exemplo, espaço da casa, da roça, da capoeira, além das estradas de seringa, castanha etc. São espaços identificados como de uma determinada família, fruto de seu trabalho (BENATTI, 2003, 2018). 
Portanto, o significado do território tradicional ajuda a compreender sua grande influência e importância para as comunidades tradicionais. As novas territorialidades devem ser reconhecidas como um componente a ser fortalecido para o desenvolvimento regional sustentável (BECKER, 2007), traduzindo um modo de vida tradicionalmente necessário à manutenção da diversidade cultural e ecológica no país. Dessa forma, "A territorialidade funciona como fator de identificação, defesa e força. Laços solidários e de ajuda mútua informam um conjunto de regras firmadas sobre uma base física considerada comum, essencial e inalienável, não obstante disposições sucessórias porventura existentes." (ALMEIDA, 2004, p. 10).

A partir de uma análise jurídica das opções de regularização da situação do PNJ, percebe-se que o conceito de território não possui uma definição unânime. Assim, território denota aspecto físico, político, biológico, cultural, econômico ou uma combinação de todos os fatores, para demonstrar a dinâmica de um espaço sempre em construção, em pertencimento a um grupo social.

Nesse contexto, ao discutir a territorialidade e gestão do território em relação ao processo de transformação territorial contemporâneo na Amazônia, Bertha Becker (2010) questiona o atual planejamento governamental, propondo a reformulação de políticas públicas que se adequem aos processos sociais territoriais. Nessa perspectiva, um importante conceito trazido é a gestão do território: “[...] gestão é um conceito associado à modernidade: é a prática estratégica, científico-tecnológica, que dirige, no tempo, a coerência de múltiplas decisões e ações para atingir uma finalidade" (BECKER, 2010, p. 4).

No caso da comunidade quilombola do Tambor, a gestão ocorrerá quando as diferentes concepções de uso e proteção dos recursos naturais forem levadas em consideração para se decidir a melhor forma de proteger o Parque Nacional do Jaú.

\section{AS COMUNIDADES TRADICIONAIS NÃO SÃO OBSTÁCULO PARA PROTEÇÃo DA NATUREZA}

Como temos discutido até o momento, não há base teórica ou empírica que sustente a concepção de que apenas as unidades de conservação de proteção integral conservam a biodiversidade, porque as comunidades tradicionais causariam impacto negativo à natureza, quebrando a capacidade de resiliência do ecossistema. Na realidade, quando discutimos a importância da proteção de sócio- e biodiversidade, pois uma se liga a outra, partimos de alguns 
pressupostos básicos; dentre eles, um trata de grupos sociais específicos que se relacionam com a natureza há centenas de anos, caso dos povos e das comunidades tradicionais ${ }^{13}$.

Os estudos de conservação da natureza, que se baseiam nas teorias da ecologia e biogeografia, evoluíram entre os séculos XIX e XX, para uma nova ideia de biodiversidade. Dessa forma, conservar e usar sustentavelmente os recursos naturais tornou-se o principal objetivo da criação de unidades de conservação da natureza. Além disso, a tentativa de conservar a natureza passou a aderir à ideia do dinamismo de sistemas, sem precisar preservar a área estaticamente, como em uma fotografia (SANTILLI, 2005).

Trata-se da inclusão não só da diversidade de espécies, como também da diversidade genética, pois os moradores, diante de múltiplas pressões, fazem escolhas, têm expectativas próprias, assim como enfrentam conflitos relacionados ao uso dos recursos naturais e à situação gerada pelas regras de uso de um Parque Nacional, às determinações familiares, comunitárias e institucionais em diferentes níveis, de acordo com o jogo de forças correntes.

Em face do exposto, a presença de comunidades tradicionais no interior de unidades de conservação seria danosa à tentativa de preservação ambiental? Em um primeiro momento, a presença de populações em boa parte das UCs existentes no Brasil é anterior a sua criação, e o patrimônio ambiental que se quer proteger é também resultado da interação entre essas populações e os recursos naturais ali existentes.

Nesse sentido, Arruda (1999) questiona a atual política ambiental, que atua ignorando o potencial conservacionista dos povos e das comunidades tradicionais, os quais historicamente protegeram as áreas que ocupam. Isso pode ser uma das únicas formas adequadas para concretizar o verdadeiro objetivo das políticas relacionadas à proteção. Nesta linha manifesta parquet ao afirmar que:

Se uma nova tendência de conservar e proteger a sociobiodiversidade vem se consolidando no debate internacional, o desafio principal para o Ministério Público Federal estaria justamente em sustentar juridicamente a equivalência dos dois interesses, manifesta em manter presentes nas Unidades de Conservação de Proteção Integral os povos tradicionais que ali residam e utilizem recursos naturais e, ao mesmo tempo, assegurar a proteção das características que ensejaram a iniciativa de conservação ambiental desses territórios. (BRASIL, 2014, p. 21).

\footnotetext{
${ }^{13}$ Estudos comprovam que os territórios indígenas e as áreas protegidas com gente são muito mais eficientes na proteção da floresta, conforme atestado por pesquisa realizada pela Rede Amazônica de Informação Socioambiental Georreferenciada (Raisg), Coordenação das Organizações Indígenas da Bacia Amazônica (Coica), Environmental Defense Fund (EDF) e Woods Hole Reseach Center (WHRC), publicada na Revista Science em 13 de outubro de 2017 (INSTITUTO SOCIOAMBIENTAL, 2017, on-line).
} 
A dicotomia homem-natureza foi consolidada com o surgimento da ciência moderna, pois o mundo natural é objeto do conhecimento empírico-racional. Para Francis Bacon e Descartes, a ciência moderna objetivava devolver o domínio do homem sobre a natureza, tornando-se válida a afirmação de Protágoras (490-420 a. C.), segundo a qual o homem é a medida de todas as coisas (BENATTI, 2014).

Pesquisadores têm destacado a interdependência entre diversidade biológica e cultural. Por isso, deve-se considerar que as culturas são construídas a partir dos elementos da natureza, e, ao mesmo tempo, elas influenciam o desenvolvimento do meio ambiente. Podemos citar os estudos de Posey (2004) e Balick (2003), e os trabalhos de Moran e Ostrom (2009) sobre florestas antropogênicas. Outros trabalhos demonstram que as populações humanas são capazes de manter e criar a biodiversidade, como argumentam Diegues (1994) e Baleé (2008). Logo, a concepção defendida acerca do conceito de natureza, especialmente a intocada, não se sustenta como justificativa para a remoção das comunidades tradicionais.

Devemos compreender que, no cenário político de definição da destinação das terras públicas, existem outros atores políticos mais fortes - o latifundiário e o grileiro -, com uma visão contrária à existência de áreas protegidas, pois enxergam nelas apenas empecilhos para a realização de seus interesses, ou seja, a incorporação de mais terras públicas para a exploração econômica e especulação.

Em comum a todas essas três percepções sobre a natureza, a criação de áreas protegidas é sempre vista como espaço de exceção, destacado do meio usual (LIMA, 2019). Se continuar, o acirramento da disputa entre "UC com ou sem gente" favorecerá um terceiro interessado nas mesmas glebas de terras, os grandes proprietários de terra ${ }^{14}$.

O conflito das comunidades tradicionais e a criação de unidades de conservação em seus territórios, objetivando a expulsão, não é uma ação recente do Poder Público. Na realidade, no Brasil, essa conduta vem desde o governo Jânio Quadros, intensificando-se no período da ditadura militar até os dias atuais (ALMEIDA; RESENDE, 2013, p. 186). Se esse conflito ainda persiste, uma das causas é a incapacidade do ICMBio como agência administradora de territórios de uso tradicionais de superar a concepção reducionista de proteção da natureza (ALMEIDA; RESENDE, 2013, p. 188).

\footnotetext{
${ }^{14}$ Segundo alguns cálculos, são milhões de hectares de terra ainda não destinados pelos governos federal e estadual na Amazônia. De acordo com Azevedo-Ramos e Moutinho (2018), são 70 milhões de hectares florestais à mercê de grileiros e desmatadores ilegais na Amazônia. No que tange ao desmatamento, 25\% de casos registrados na Amazônia, entre 2010 e 2015, aconteceram nessas áreas públicas desprotegidas, ou seja, nas terras públicas estaduais e federais que não foram destinadas a nenhum uso.
} 
Uma das lições abstraídas da criação de um parque nacional em território das comunidades tradicionais, em particular o PARNA-Jaú, é o fato de o território conformar-se em espaço físico das atividades familiares e de grupo, substrato material da atividade humana e, consequentemente, lócus de relações de poder e estratégias identitárias. Em síntese: de um lado, manifesta-se como um processo que associa desterritorialização e exclusão social de um grupo social; de outro, apresenta-se como um processo complexo de reterritorialização, na formação de novas territorialidades (HAESBAERT, 2003).

O conflito entre as concepções de preservação da natureza e a garantia dos direitos ao território das comunidades tradicionais, especificamente o quilombo do Tambor, deixa claro que a tensão induz à formulação de novas territorialidades, nas quais a afirmação étnica preexistente é negada pelas "regras" legais. Dessa forma, essas regras restringem e obrigam as comunidades tradicionais a saírem da área historicamente ocupada. Esse cenário conduz a uma reterritorialização da área, com o aparecimento de figuras jurídicas distintas (a unidade de conservação e o território quilombola), razão por que a pretensa contradição apresentada pouco muda em relação ao objetivo final buscado, a proteção da natureza.

\section{CONSIDERAÇÕES FINAIS E AS POSSÍVEIS SOLUÇÕES PARA OS CONFLITOS NO PARNA-Jaú}

Nas últimas décadas, a preocupação, por parte dos Estados-nação, com o respeito aos direitos diferenciados dos povos indígenas e das comunidades tradicionais cresceu de forma acelerada, notavelmente em relação ao reconhecimento fundiário e territorial (LITTLE, 2004).

Em relação à busca de conciliação e mediação dos conflitos socioambientais no Parque Nacional do Jaú, fica claro o desrespeito aos direitos das comunidades tradicionais que existiam anteriormente à criação da unidade de conservação, o que levou a novas formas de resistência com a reivindicação do reconhecimento do Quilombo do Tambor.

Entretanto, reconhecer o respeito como forma de superar qualquer barreira jurídica indica que a mera discussão a respeito da categorização das comunidades tradicionais não é maior do que o cumprimento do dever do Estado em zelar pela proteção à diversidade cultural. Deve-se admitir que as comunidades tradicionais, as quais residem ou residiam no Parque, não tiveram seus direitos territoriais assegurados, além de as alternativas apontadas pela legislação ambiental (art. 42 da Lei 8.995/2000), mediante à qual os moradores do PNJ devem ser indenizados ou reassentados em outra área, restringirem direitos constitucionais. 
Passados 41 anos de criação do Parque e 21 anos da promulgação da Lei do SNUC, a situação para a comunidade do Tambor avançou pouco no que se refere ao cumprimento da lei ou à proposição de uma alternativa que respeite a sociobiodiversidade existente na área. Portanto, as tentativas de conciliar a criação da unidade de conservação da natureza com a presença das comunidades tradicionais foram infrutíferas ${ }^{15}$.

A grande divergência entre a proteção da natureza e o respeito ao direito ao território das comunidades tradicionais só ocorre porque, no momento da criação da unidade de conservação, não foi aceita a possibilidade de se trabalhar com uma modalidade de proteção ambiental mais flexível e mais adequada à coexistência humana, não se reconheceu a importância de conciliar a conservação ambiental e o desenvolvimento social (REIS, 2013; MENDES, 2008).

Assim, o que se deve fazer agora é encontrar soluções possíveis para minimizar as consequências da sobreposição, a exemplo de uma recategorização do Parque, respeitando o direito das comunidades tradicionais no uso do seu território, pois proteger o meio ambiente faz parte de seu cotidiano. Outras possíveis soluções foram apontadas por Mauro Almeida e Roberto Resende, ao afirmarem que:

Uma real mudança de política exigiria a devolução dos sistemas de cogestão comunitária nos Territórios Tradicionais e a criação de um órgão similar à FUNAI para agrupar políticas destinadas a esses territórios, fora do âmbito do ICMBio, bem como a reformulação do SNUC de modo a reconhecer de direito o papel dos Povos e Comunidades Tradicionais para a proteção e uso sustentável dos territórios que ocupam tradicionalmente. (ALMEIDA; RESENDE, 2013, p. 194).

Como alternativa para resolução do conflito, podemos pensar também na promoção da gestão conjunta entre os órgãos competentes, garantindo a participação das populações locais envolvidas, a fim de respeitar o seu modo de vida - algo que poderá ser concretizado com a assinatura de termos de compromisso que assegurem o uso de recursos naturais pelas comunidades tradicionais, sem a perspectiva de futuro reassentamento (ABIRACHED; BRASIL; SHIRAISHI, 2010). Nesse caso, seria trabalhar com a "possibilidade de dupla

\footnotetext{
${ }^{15}$ Por intermédio da Câmara de Conciliação e Arbitragem da Administração Federal (CCAF), o governo federal buscou soluções para a sobreposição de Unidades de Conservação de Proteção Integral Federais em territórios quilombolas desde o ano de 2007, mas não conseguiu sucesso. Em particular sobre o conflito PARNA-Jaú e o quilombo Tambor, ver o Processo CCAF: 00400.009941-2010-86 (CHACPE, 2014, p. 106). Em reunião de Conciliação e Arbitragem da Administração Federal (CCAF) da AGU, realizada em 2014, chegou-se à decisão de transferir os moradores do Tambor, com a realocação para outra área, acordada entre o ICMBio, o INCRA e a comunidade. Contudo, em maio de 2014, o Ministério Público Federal do Amazonas entrou com uma ação civil pública na justiça federal, solicitando ao INCRA a conclusão do processo de titulação da comunidade do Tambor, ou seja, contrária à realocação (LEITE, 2015, p. 102-103).
} 
afetação entre os parques e reservas e a presença das comunidades quilombolas" (CHACPE, 2014, p. 134).

As possíveis soluções são conhecidas. No momento, trata-se de uma questão de pressão social e mudança da concepção governamental, aceitando o fato de os fundamentos preservacionistas e socioambientalistas poderem ser conciliados. Para isso, devemos considerar o pressuposto do reconhecimento das comunidades tradicionais como portadoras de conhecimento e técnicas de uso e manejo dos recursos naturais de baixo impacto à natureza, e de que uma unidade de conservação "com gente" estará mais protegida do que uma área protegida "sem gente".

\section{REFERÊNCIAS}

ABIRACHED, Carlos Felipe de Andrade; BRASIL, Daniel; SHIRAISHI, Juliana Costa. Áreas Protegidas e Comunidades tradicionais: conflitos e soluções. In: ENCONTRO NACIONAL DA ASSOCIAÇÃO NACIONAL DE PÓS-GRADUAÇÃO E PESQUISA EM AMBIENTE E SOCIEDADE, 5., 2010, Florianópolis. Anais... São Paulo: ANPPAS, 2010.

ALMEIDA, Alfredo Wagner Berno de. Terras Tradicionalmente Ocupadas: processos de territorialização e movimentos sociais. Revista Brasileira Estudos Urbanos e Regionais, Rio de Janeiro, v. 6, n. 1, p. 9-32, maio 2004.

ALMEIDA, Alfredo Wagner Berno de. Reconfiguração das agroestratégias: novo capítulo da guerra ecológica. In: SAUER, Sergio; ALMEIDA, Wellington (Org.). Terras e Territórios na Amazônia. Brasília: UNB; Abaré, 2011. p. 93-113.

ALMEIDA, Mauro William Barbosa; RESENDE, Roberto Sanches. Uma Nota sobre Comunidades Tradicionais e Unidades de Conservação. Revista Ruris, Campinas, v. 7, n. 2 , p. 185-195, set. 2013.

ARRUDA, Rinaldo. Populações tradicionais e a proteção dos recursos naturais em unidades de conservação. Revista Ambiente \& Sociedade, Ano II, N. 5, p. 79-93, 2o Semestre de 1999. 
ARRUTI, José Maurício. Mocambo. Antropologia e história do processo de formação quilombola. Bauru: EDUSC. 2006.

AZEVEDO-RAMOS, Cláudia; MOUTINHO, Paulo. No man's land in the Brazilian Amazon: Could undesignated public forests slow Amazon deforestation? Land Use Policy, v. 73, p. 125-127, April 2018.

BALEÉ, William. Sobre a Indigeneidade das Paisagens. Revista de Arqueologia, Pelotas, v. 21, n. 2, p. 9-23, 2008.

BALICK, M. J. Traditional Knowledge: lessons form the past, lessons for the future. In: CONFERENCE ON BIODIVERSITY AND BIOTECHNOLOGY AND THE PROTECTION OF TRADICIONAL KNOWLEDGE, 2003, Washington D.C. Proceedings... Washington D.C.: Washington University, 2003. Disponível: $<$ tinyurl.com/y6lfp9h7>. Acesso em: 15 maio 2019.

BARRETO FILHO, Henyo Trindade. Comunidades tradicionais: introdução à crítica da ecologia política de uma noção. In: MURRIETA, Rui; ADAMS, Cristina; NEVES, Walter (Org.). Sociedades Caboclas Amazônicas: modernidade e invisibilidade. São Paulo: Anna Blume, 2006, p. 109-144.

BARRETTO FILHO, Henyo Trindade. Da Nação ao planeta através da natureza: uma abordagem antropológica das unidades de conservação de proteção integral na Amazônia brasileira. 2001. 536p. Tese (Doutorado em Antropologia Social) - FFLCH, USP, São Paulo, 2001.

BECKER, Bertha Koiffmann. A Amazônia e a política ambiental brasileira. In: SANTOS, S.; BECKER, B. (Eds.). Território, territórios: ensaios sobre o ordenamento territorial. 3. ed. Rio de Janeiro: Lamparina, 2007. p. 22-42.

BECKER, Bertha Koiffmann. Novas territorialidades na Amazônia: desafio às políticas públicas. Boletim Museu Paraense Emílio Goeldi. Revista Ciências Humanas, Belém, v. 5, n. 1, p. 17-23, jan.- abr. 2010. 
BENATTI, José Heder. Posse agroecológica e manejo florestal. Curitiba: Juruá, 2003.

BENATTI, José Heder. O conceito de meio ambiente no art. $3 .^{\circ}$ da Lei n. ${ }^{\circ} 6.938 / 1981 \mathrm{In}$ : Dias, Jean Carlos; Gomes, Marcus Alan de Melo (Org.). Direito e Desenvolvimento. Rio de Janeiro: Forense; São Paulo: Método, 2014. p. 247-262.

BENATTI, José Heder. Das terras tradicionalmente ocupadas ao reconhecimento da diversidade social e de posse das comunidades tradicionais na Amazônia. In: UNGARETTI, Débora et al. (Org.). Propriedades em transformação: abordagens multidisciplinares sobre a propriedade no Brasil. São Paulo: Blucher, 2018. p. 193-214.

BRASIL. Decreto $\mathbf{n}^{\mathbf{0}}$ 85.200, de 24 de setembro de 1980. Cria, no Estado do Amazonas, o Parque Nacional do Jaú. Brasília, DF: Presidência da República, [1980]. Disponível em: $<$ tinyurl.com/y2vm6azb>. Acesso em: 30 abr. 2020.

BRASIL. Decreto n 86.061, de 2 de junho de 1981. Cria Estações Ecológicas, e dá outras providências. Brasília, DF: Presidência da República, [1981]. Disponível em: $<$ tinyurl.com/yyuuozm7>. Acesso em: 30 abr. 2020.

BRASIL. [Constituição (1988)]. Constituição da República Federativa do Brasil. Brasília, DF: Presidência da República, [1988]. Disponível em: <tinyurl.com/czskwlw>. Acesso em: 30 abr. 2020.

BRASIL. Lei n. 9.985, de 18 de julho de 2000. Regulamenta o artigo 225 da Constituição Federal e institui o Sistema Nacional de Unidades de Conservação e das outras providências. Brasília, DF: Presidência da República, [2000a]. Disponível em: <tinyurl.com/y2wrf66c>. Acesso em: 30 abr. 2020.

BRASIL. Ministério do Meio Ambiente. Convenção sobre a Diversidade Biológica - CDB. Cópia do Decreto Legislativo no. 2, de 5 de junho de 1992. Brasília: DF: MMA, 2000b.

BRASIL. Decreto $n^{0}$ 4.887, de 20 de novembro de 2003. Regulamenta o procedimento para identificação, reconhecimento, delimitação, demarcação e titulação das terras ocupadas por remanescentes das comunidades dos quilombos de que trata o art. 68 do Ato das Disposições Constitucionais Transitórias. Brasília, DF: Presidência da República, [2003]. Disponível em: $<$ tinyurl.com/y714xqu8>. Acesso em: 30 abr. 2020.

BRASIL. Decreto $\mathbf{n}^{0}$ 5.758, de 13 de abril de 2006. Institui o Plano Estratégico Nacional de Áreas Protegidas - PNAP, seus princípios, diretrizes, objetivos e estratégias, e dá outras providências. Brasília, DF: Presidência da República, [2006]. Disponível em:

$<$ tinyurl.com/y3yqqlxn>. Acesso em: 30 abr. 2020.

BRASIL. Decreto $\mathbf{n}^{\mathbf{0}}$ 6.040, de 7 de fevereiro de 2007. Institui a Política Nacional de Desenvolvimento Sustentável dos Povos e Comunidades Tradicionais. Brasília, DF: Presidência da República, [2007]. Disponível em: <tinyurl.com/y5gby8bg>. Acesso em: 30 abr. 2020.

BRASIL. Instrução Normativa ICMBIO Nº9, de 05 de dezembro de 2014. Disciplina as diretrizes, normas e procedimentos para formação, implementação e modificação na composição de Conselhos Gestores de Unidades de Conservação Federais, [2014]. Disponível em <tinyurl.com/y5gby8bg>. Acesso em: 30 abr. 2020. 
BRASIL. Lei no 11.799, de 29 de outubro de 2008. Transforma a Estação Ecológica de Anavilhanas, criada pelo Decreto no 86.061, de 2 de junho de 1981, em Parque Nacional de Anavilhanas. Brasília, DF: Presidência da República, [2008]. Disponível em: $<$ tinyurl.com/y3qf97ua $>$. Acesso em: 30 abr. 2020.

BRASIL. Ministério do Meio Ambiente. Plano de Manejo do Parque Nacional Montanhas do Tumucumaque. Macapá: MMA; IBAMA, 2009.

BRASIL. Ministério Público Federal. Territórios de povos e comunidades tradicionais e as unidades de conservação de proteção integral: alternativas para o asseguramento de direitos socioambientais. Brasília: MPF, 2014.

BRASIL. Ministério do Meio Ambiente. Povos Indígenas, Quilombolas, Comunidades Tradicionais, Assentados da Reforma Agrária e Unidades de Conservação Federais: diagnóstico e plano de ação para a gestão dos conflitos territoriais. Brasília: Ministério do Meio Ambiente; Instituto Chico Mendes de Conservação da Biodiversidade, [20--].

BRASIL. Superior Tribunal Federal. Ação Direta de Inconstitucionalidade - ADI 3239. Órgão Julgador: Tribunal Pleno. Relator Ministro Cezar Peluso. Julgado em 08/02/2018, Publicado DJ em 01/02/2019. Brasília: STF, [201-].

CALDENHOF, Satya Bottin Loeb; FERREIRA, Lúcia. As Três Margens do Rio Unini e o Novo Processo de Ordenamento Territorial. In: ENCONTRO NACIONAL DA ASSOCIAÇÃO NACIONAL DE PÓS-GRADUAÇÃO E PESQUISA EM AMBIENTE E SOCIEDADE, 6., 2012, Belém. Anais... São Paulo: ANPPAS, 2012.

CAMPOS, Simone Vieira de. Jaú em Jogo: mudanças sociais e conservação ambiental no Parque Nacional do Jaú (AM). 2006. 242 f. Tese (Doutorado em Ciências Sociais) Universidade Estatual de Campinas, Campinas, 2006.

CHACPE, Juliana Fernandes. Territórios quilombolas e unidades de conservação de proteção integral: desafios da conciliação na Administração Federal. 2014. 157 f.

Dissertação (Mestrado em Desenvolvimento Sustentável) - Universidade de Brasília, Brasília, 2014.

CHAGAS, Míriam de Fátima. Da invisibilidade jurídica aos direitos de coletividades: fazer antropológico em terra de quilombos. In ZHOURI, Andréa (Org.), Desenvolvimento, reconhecimento de direitos e conflitos territoriais. Belo Horizonte: Ed. UFMG. 2010. p. 255-297.

CREADO, Eliana Santos Junqueira; MENDES, Ana Beatriz Vianna; FERREIRA, Lúcia da Costa; CAMPOS, Simone Vieira de. Entre "Tradicionais" e "Modernos": negociações de direitos em duas unidades de conservação da Amazônia brasileira. Revista Ambiente \& Sociedade, Campinas, v. XI, n. 2, p. 255-271, jul.-dez. 2008.

CUNHA, Manoela Carneiro da; ALMEIDA, Mauro Willian Barbosa. Comunidades tradicionais e Conservação Ambiental. In: CAPOBIANCO, João P. R. et al (Org.). Biodiversidade na Amazônica: Avaliação e Ações Prioritárias para a Conservação, Uso Sustentável e Repartição de Benefícios. São Paulo: Estação Liberdade; Instituto Socioambiental, 2001. p. 184-193. 
DIEGUES, Antonio Carlos Sant'Ana. O Mito Moderno da Natureza Intocada. São Paulo, NUPAUB, Universidade de São Paulo, 1994.

FUNDAÇÃO VITÓRIA AMAZÔNICA. Plano de Manejo do Parque Nacional do Jaú. Manaus: Fundação Vitória Amazônica; IBAMA, 1998.

HAESBAERT, Rogério. Da Desterritorialização à Multiterritorialidade. Boletim Gaúcho de Geografia, Porto Alegre, n. 29, p. 11-24, jan. 2003.

HAFFER, J.; PRANCE, G. T. Impulsos climáticos da evolução na Amazônia durante o Cenozóico: sobre a teoria dos Refúgios da diferenciação biótica. Revista de Estudos Avançados. São Paulo, v. 16, n. 46, p. 175-206, dez. 2002.

INSTITUTO SOCIOAMBIENTAL. Novos dados reforçam que territórios indígenas e áreas protegidas barram desmatamento. Instituto Socioambiental, [on-line], 1 nov. 2017. Disponível em: <tinyurl.com/yyokc3x8 > Acesso em: 24 jan. 2021.

INSTITUTO SOCIOAMBIENTAL. Parque Nacional de Anavilhanas. Unidades de Conservação no Brasil, [on-line], [20--]. Disponível em: <tinyurl.com/yxn4ulg6>. Acesso em: 24 jan. 2021.

INTERNATIONAL UNION FOR CONSERVATION OF NATURE. About. What is a protected area? IUCN, [on-line], [20--]. Disponível em: <tinyurl.com/y3vulwg3>. Acesso em: 30 abr. 2020.

JOHN, Liana. Amazônia Central é declarada patrimônio natural da humanidade. Instituto Socioambiental, [on-line], 3 jul. 2003. Republicado do jornal O Estado de. S Paulo. Disponível: <tinyurl.com/y4m5ggdo>. Acesso em: 23 jan. 2021.

LEITE, Carla Vladiane Alves. A Sobreposição de Direitos da Comunidade Quilombola do Tambor e a Unidade de Conservação Parque Nacional do Jaú: Uma Análise Crítica. 2015. 113 f. Dissertação (Mestrado em Direito Ambiental) - Universidade do Estado do Amazonas, Manaus, 2015.

LIMA, Deborah. Áreas Protegidas na Amazônia e o Porvir: por uma composição possível. In: GALÚCIO, Ana Vilacy; PRUDENTE, Ana Lucia, (Org.). Museu Goeldi: 150 anos de Ciência na Amazônia. Belém: Museu Paraense Emílio Goeldi, 2019. p. 222-247.

LITTLE, Paul. Territórios sociais e povos tradicionais no Brasil. Por uma antropologia da territorialidade. Rio de Janeiro: Tempo Brasileiro, 2004.

MENDES, Ana Beatriz Vianna Mendes; CREADO, Eliana Santos Junqueira; CAMPOS, Simone Vieira de; FERREIRA, Lúcia da Costa Ferreira. Processos Decisórios Envolvendo Populações que Residem no Parque Nacional do Jaú (AM). In: ENCONTRO NACIONAL DA ASSOCIAÇÃO NACIONAL DE PÓS-GRADUAÇÃO E PESQUISA EM AMBIENTE E SOCIEDADE, 3., 2006, Brasília. Anais... São Paulo: ANPPAS, 2006.

MENDES, Ana Beatriz Vianna. Ambientalização de direitos étnicos e etnização das arenas ambientais: comunidades tradicionais e povos indígenas da Reserva de Desenvolvimento Sustentável de Mamirauá (AM). In: REUNIÃO BRASILEIRA DE ANTROPOLOGIA, 26., 2008, Porto Seguro. Anais... Brasília: ABA, 2008. 
MORAN, Emilio Federico; OSTROM, Elionor (Org.). Ecossistemas Florestais: interação homem-ambiente. São Paulo: Editora Senac; Edusp, 2009.

PEREIRA, Polyana Faria; SCARDUA, Fernando Paiva. Espaços territoriais especialmente protegidos: conceito e implicações jurídicas. Revista Ambiente e Sociedade, Campinas, v. XI, n.1, p. 81-97, jan./jun. 2008.

POSEY, Darrel A. Indigenous knowledge, biodiversity, and international rights: learning about forest from the Kayapó Indians of the Brazilian Amazon. In: PLENDELEITH, Kristiana. (Ed.). Indigenous knowledge and ethics: a Darrel A. Posey Reader. London: Routledge, 2004. p. 133-140.

RED AMAZÓNICA DE INFORMACIÓN SOCIOAMBIENTAL GEORREFERENCIADA. Cartografía Histórica de Áreas Naturales Protegidas y Territorios Indígenas en la Amazonía. [S. 1.]: RAISG, 2016. Disponível em: <tinyurl.com/yy67sf65>. Acesso em: 20 nov. 2020.

REIS, Marise Batista dos. Arengas e psicas: as reações populares à criação da REDES Mamirauá e ao manejo sustentável e participativo dos recursos naturais. 2003. $86 \mathrm{f}$. Dissertação (Mestrado em Desenvolvimento, Agricultura e Sociedade) - Universidade Federal Rural do Rio de Janeiro, Rio de Janeiro, 2003.

SANTILLI, Juliana. Socioambientalismo e Novos Direitos: Proteção Jurídica à diversidade biológica e cultural. São Paulo: Peirópolis, 2005.

SHIRAISHI NETO, Joaquim. Novos movimentos sociais e padrões jurídicos no processo de redefinição da região Amazônica. In SHIRAISHI NETO, Joaquim (Org.). Meio Ambiente, território \& práticas jurídicas: enredos em conflito. São Luis: EDUFMA. 2011. pp. 23-52.

SOUZA FILHO, Carlos Frederico Marés de. Os povos invisíveis. In: PRIOSTE, Fernando Gallardo Vieira; Araújo, Eduardo Fernandes de (Org.). Direito Constitucional Quilombola: Análises sobre a Ação Direta de Inconstitucionalidade $\mathrm{n}^{\circ}$ 3239. Rio de Janeiro: Lumes Juris, 2015. p. 7-12.

TRECCANI, Girolamo Domenico. Terras de Quilombo: caminhos e entraves do processo de titulação. Belém: Secretaria Executiva de Justiça. Programa Raízes, 2006.

VIANNA, Lucila Pinsard. De Invisíveis a Protagonistas: comunidades tradicionais e unidades de conservação. São Paulo: Annablume; Fapesp, 2008.

Data de recebimento: 18.12 .2020

Data de aprovação: 21.02.2021 
